\title{
High baseline serum total and LDL cholesterol levels are associated with MDR1 haplotypes in Brazilian hypercholesterolemic individuals of European descent
}

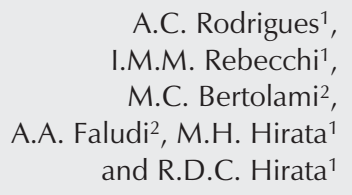

A.C. Rodrigues ${ }^{1}$,

I.M.M. Rebecchi',

M.C. Bertolami²,

A.A. Faludi ${ }^{2}$, M.H. Hirata ${ }^{1}$ and R.D.C. Hirata ${ }^{1}$

\author{
${ }^{1}$ Departamento de Análises Clínicas e Toxicológicas, \\ Faculdade de Ciências Farmacêuticas, Universidade de São Paulo, \\ São Paulo, SP, Brasil \\ ${ }^{2}$ Instituto Dante Pazzanese de Cardiologia, São Paulo, SP, Brasil
}

\author{
Correspondence \\ R.D.C. Hirata \\ Faculdade de Ciências Farmacêuticas \\ Universidade de São Paulo \\ Av. Prof. Lineu Prestes, 580, B17 \\ 05508-900 São Paulo, SP \\ Brasil \\ Fax: +55-11-3813-2197 \\ E-mail: rosariohirata@usp.br
}

Research supported by FAPESP (No. 03/02086-8) and CNPq (No. 473694/03-4).

Received June 18, 2004 Accepted May 20, 2005

\begin{abstract}
The MDRl gene encodes the P-glycoprotein, an efflux transporter with broad substrate specificity. P-glycoprotein has raised great interest in pharmacogenetics because it transports a variety of structurally divergent drugs, including lipid-lowering drugs. The synonymous single-nucleotide polymorphism $\mathrm{C} 3435 \mathrm{~T}$ and the nonsynonymous single-nucleotide polymorphism G2677T/A in MDR1 have been indicated as potential determinants of variability in drug disposition and efficacy. In order to evaluate the effect of G2677T/A and C3435T MDR1 polymorphisms on serum levels of lipids before and after atorvastatin administration, 69 unrelated hypercholesterolemic individuals from São Paulo city, Brazil, were selected and treated with 10 $\mathrm{mg}$ atorvastatin orally once daily for four weeks. MDR1 polymorphisms were analyzed by PCR-RFLP. C3435T and G2677T polymorphisms were found to be linked. The allelic frequencies for $\mathrm{C} 3435 \mathrm{~T}$ polymorphism were 0.536 and 0.464 for the $3435 \mathrm{C}$ and $3435 \mathrm{~T}$ alleles, respectively, while for G2677T/A polymorphism allele frequencies were 0.580 for the $2677 \mathrm{G}$ allele, 0.384 for the $2677 \mathrm{~T}$ allele and 0.036 for the $2677 \mathrm{~A}$ allele. There was no significant relation between atorvastatin response and $M D R 1$ polymorphisms (repeated measures ANOVA; $\mathrm{P}>0.05)$. However, haplotype analysis revealed an association between T/T carriers and higher basal serum total (TC) and LDL cholesterol levels (TC: $303 \pm 56$, LDL-C: $216 \pm 57 \mathrm{mg} / \mathrm{dl}$, respectively) compared with non-T/T carriers (TC: $278 \pm 28$, LDL-C: $189 \pm 24$ $\mathrm{mg} / \mathrm{dl}$; repeated measures ANOVA/Tukey test; $\mathrm{P}<0.05)$. These data indicate that $M D R 1$ polymorphism may have an important contribution to the control of basal serum cholesterol levels in Brazilian hypercholesterolemic individuals of European descent.
\end{abstract}

Key words - MDR1 gene

- Hypercholesterolemia

- Statins

- Single nucleotide

polymorphism

- Pharmacogenetics 


\section{Introduction}

Statins are 3-hydroxy-3-methylglutaryl co-enzyme A (CoA) reductase (HMGR) inhibitors that have an effective cholesterol lowering effect. Atorvastatin is an active hydroxy acid statin that reduces low-density lipoprotein (LDL) cholesterol by 40 to $60 \%$ at single daily doses of 10 to $80 \mathrm{mg}$ (1). Atorvastatin undergoes varying degrees of metabolism in both animals and humans, catalyzed primarily by CYP3A4, an isoform of cytochrome P450, in the liver and gut (2). Other reported biotransformation pathways include lactonization of statin hydroxy acid and $\beta$-oxidation at the common dihydroxy heptanoic or heptanoic acid side chain (3). The statin acids are converted to the corresponding lactones by the acyl glucuronide intermediate, as demonstrated by Prueksaritanont et al. (4). Both acyl glucuronide and acyl CoA derivatives may revert to the statin acids by hydrolysis. Similar considerations apply to oxidative metabolites of the statins. The statin lactones are hydrolyzed to their open acids chemically or enzymatically by esterases or the recently identified paraoxonases. Atorvastatin and its metabolites are excreted primarily into the bile (1) by transporters, represented especially by the ATPbinding cassette (ABC) family (5).

$\mathrm{ABC}$ transporters are a superfamily of integral transmembrane proteins that uses energy of ATP hydrolysis to translocate a broad spectrum of molecules across the cell membrane. $\mathrm{ABC}$ proteins have transmembrane domains, intracellular ATP-binding domains, and a substrate-binding domain (6).

$\mathrm{ABCB} 1$ is a $170-\mathrm{kDa}$ transporter protein named P-glycoprotein (P-gp) that has been associated with the transport of cellular lipids and drugs (6). P-gp is involved in the elimination of atorvastatin, which has been described as an inhibitor of P-gp (7). Constitutive expression of P-gp transporter in normal tissues has been shown to play an important role in drug disposition and response (reviewed in Ref. 8). The co-localization of P-gp with the drug-metabolizing enzyme CYP3A4 in the small intestine and liver suggests its role in the oral bioavailability, distribution, and excretion of drugs (9).

Expression of $\mathrm{P}-\mathrm{gp}$ is regulated by the pregnane $\mathrm{X}$ receptor (PXR), a ligand-activated transcription factor that coordinately stimulates the expression of a large program of genes involved in the solubilization and excretion of xenobiotics from the body. Among them are those encoding P450 enzymes, UDP-glucuronosyltransferases, glutathione-S-transferase and various transporters, such as multidrug resistance-associated protein 2 and organic anion transporter peptide 2 (10). It has been reported that statins may be ligands for PXR since lovastatin was characterized as a PXR activator (11).

$\mathrm{P}$-gp is encoded by a polymorphic gene named multidrug resistance $1(M D R I)$ located on chromosome 7. The MDRl gene has more than 20 polymorphisms, some of which have been associated with altered Pgp expression and activity in vivo (8).

The silent C3435T (exon 26) and the G2677T/A (exon 21), that lead to the amino acid exchanges G2677T (Ala893Ser) and G2677A (Ala893Thr), are common MDRl polymorphisms. The frequencies of $M D R I$ $3435 \mathrm{~T}$ and $2677 \mathrm{~T}$ alleles are influenced by ethnicity. Caucasian and Asian individuals have a higher frequency of the $3435 \mathrm{~T}$ allele (37 to $66 \%$ ) than African individuals (10 to $27 \%)(8,12,13)$. The frequency of the $2677 \mathrm{~T}$ allele is also higher in Asians and Caucasians (38 to 62\%) than in African Americans (15\%) (8,14-16). On the other hand, the 2677A allele frequency is higher in Japanese $(15$ to $22 \%)(14,17)$ than in Caucasians (2 to $4 \%)(15,18,19)$.

It has been reported that $\mathrm{C} 3435 \mathrm{~T}$ and G2677T/A polymorphisms influence the duodenal expression of P-gp and alter the absorption and/or disposition of many drugs $(20,21)$.

C3435T polymorphism was found to be 
associated with variation in intestinal P-gp levels, influencing the uptake of orally administered P-gp substrates such as digoxin (22), fexofenadine (16) and cyclosporine (23). Subjects carrying the 3435TT genotype have remarkably lower duodenal P-gp expression and higher plasma digoxin levels in comparison to subjects with $\mathrm{CC}$ or CT genotypes $(22,24,25)$. In contrast to these observations, lower plasma digoxin levels after orally administered digoxin and higher $M D R 1$ expression in duodenal enterocytes were found in Japanese individuals carrying the 3435 T allele $(20,26)$.

The MDR1 G2677T/A polymorphism has also been associated with variations of P-gp activity. In vitro experiments have shown that cells expressing the $2677 \mathrm{~T}$ variant have an enhanced efflux of digoxin when compared to those expressing the $2677 \mathrm{G}$ allele (16). Moreover, individuals carrying the 2677T allele had higher P-gp activity in vivo, measured by plasma fexofenadine levels, than those with the $2677 \mathrm{G}$ allele (16). MDRI mRNA expression relative to villin mRNA in duodenal enterocytes was higher in subjects carrying the $2677 \mathrm{~T}$ or $2677 \mathrm{~A}$ polymorphic alleles (14).

Since it has been proposed that atorvastatin alters P-gp activity, it is possible that variations in MDRl may also affect lipid response to atorvastatin. The present study was designed to evaluate the effects of human MDRl polymorphisms, specifically G2677T/A and C3435T, on serum levels of lipids before and after atorvastatin administration to unrelated Brazilian individuals with hypercholesterolemia.

\section{Material and Methods}

\section{Subjects and study protocol}

Sixty-nine unrelated individuals (28 men, 41 women, mean age: 59 years) were studied. They were admitted to the Dante Pazzanese Institute of Cardiology (São Paulo,
SP, Brazil) from 2001 to 2003, with primary hypercholesterolemia, according to NCEP (27). Individuals with plasma triglycerides above $400 \mathrm{mg} / \mathrm{dl}$, with hypothyroidism or diabetes mellitus or treated with oral contraceptives were not included in the study. The characteristics of the subjects are presented in Table 1.

Four weeks before the study all subjects met with a dietitian and were instructed to consume a low cholesterol diet. One week before the start of atorvastatin treatment, all subjects were evaluated for fasting serum levels of glucose, lipids and hepatic enzymes. Individuals with LDL cholesterol higher than $160 \mathrm{mg} / \mathrm{dl}$ were started on atorvastatin therapy, $10 \mathrm{mg}$ orally once daily for four weeks. After treatment, subjects underwent another

Table 1. Characteristics of Brazilian hypercholesterolemic individuals of European descent.

\begin{tabular}{lc}
\hline & $\begin{array}{c}\text { Hypercholesterolemic } \\
\text { individuals }\end{array}$ \\
\hline Sex & \\
Female & $59.4 \%(41)$ \\
Male & $40.6 \%(28)$ \\
Age (years) & \\
Mean \pm SD & $59 \pm 12$ \\
Range & $32-79$ \\
Risk factors & \\
Arterial hypertensiona & $62.7 \%\left(42 / 67^{*}\right)$ \\
Tobacco smoking & $16.0 \%(11)$ \\
Menopause & $92.7 \%(38)$ \\
Men $\geq 45$ years & $75.0 \%(21)$ \\
Women $\geq 55$ years & $75.6 \%(31)$ \\
Family history of coronary & $32.6 \%\left(22 / 68^{*}\right)$ \\
$\quad$ artery diseasec & \\
Concomitant medication & \\
Antihypertensived & \\
\hline
\end{tabular}

Data regarding sex, risk factors and concomitant medication are reported as percent with the number of individuals given in parentheses. aArterial pressure $\geq 140 / 90 \mathrm{mmHg}$; ${ }^{b}$ no hormonal replacement therapy; ${ }^{c}$ first-degree relationship for men below 55 years and for women below 65 years;

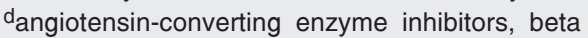
blockers, thiazide diuretics, "potassium sparing" diuretics, and calcium channel blockers. *Individuals whose clinical characteristics were not available were not included in the statistical analysis. 
evaluation of fasting serum levels of glucose, lipids and hepatic enzymes. The study protocol was approved by Dante Pazzanese Institute of Cardiology Ethics Committee and informed consent was obtained from each patient.

\section{Lipid and lipoprotein measurements}

Blood samples were collected from the individuals after an overnight fast, before and after atorvastatin administration. Serum total cholesterol, high-density lipoprotein (HDL) cholesterol, and triglyceride concentrations were measured using standard enzymatic methods with an automated analyzer (Hitachi 912, Hitachi Ltd., Tokyo, Japan). HDL cholesterol was measured after phosphotungstic acid and magnesium precipitation. LDL and very low-density lipoprotein (VLDL) cholesterol concentrations were calculated using the Friedwald formula (28).

\section{Genomic DNA analysis}

Genomic DNA was extracted from EDTA-anticoagulated blood by a saltingout procedure optimized in our laboratory (29). G2677T, G2677A, and C3435T MDR1 polymorphic regions were amplified by the polymerase chain reaction (PCR). PCR assays were performed with $50 \mathrm{ng}$ genomic DNA, amplification buffer (50 mM KCl, 20 $\mathrm{mM}\left(\mathrm{NH}_{4}\right)_{2} \mathrm{SO}_{4}, 2 \mathrm{mM} \mathrm{MgCl} 2,75 \mathrm{mM}$ Tris$\mathrm{HCl}, \mathrm{pH}$ 9.0), $200 \mu \mathrm{M}$ primers, and $0.5 \mathrm{U}$ DNA polymerase (Biotools B\&M Labs., S.A., Madrid, Spain). For both G2677T and G2677A genotyping, the forward primer 5'TTGTTTTGCAGGCTATAGGTTCC-3' and the reverse were used as described previously (15). For C3435T polymorphism, we designed the forward and reverse primers 5'TCCTTAATCTCACAGTAACTTGGCA-3' and 5'-ATGAAGGCATGTATGTTGGCCT3 ', respectively. The thermal cycler protocol consisted of initial denaturation at $98^{\circ} \mathrm{C}$ for 3 min followed by 35 cycles of denaturation at $94^{\circ} \mathrm{C}$ for $1 \mathrm{~min}$, annealing at $60^{\circ} \mathrm{C}$ for $2 \mathrm{~min}$ and extension at $72^{\circ} \mathrm{C}$ for $2 \mathrm{~min}$. Amplification was carried out in a thermal cycler, PTC-200 (MJ Research Inc., Walthan, MA, USA). PCR products were analyzed by $1.5 \%$ agarose gel electrophoresis after ethidium bromide staining.

G2677T, G2677A and C3435T polymorphisms were detected by digestion of PCRamplified products using the restriction enzymes BshNI, RsaI and MboI, respectively. Enzymatic digestions were performed at $37^{\circ} \mathrm{C}$ for $1 \mathrm{~h}$ in a total volume of $10 \mu \mathrm{l}$ using $1 \mathrm{U}$ restriction endonuclease and $1 \mathrm{x}$ restriction buffer (33 mM Tris-acetate, $10 \mathrm{mM}$ magnesium acetate, $66 \mathrm{mM}$ potassium acetate, 0.1 $\mathrm{mg} / \mathrm{ml} \mathrm{BSA}, \mathrm{pH}$ 7.9). Restriction fragments were identified by $8 \%$ polyacrylamide gel electrophoresis after silver staining.

\section{Statistical analysis}

Genotype distribution and allelic frequency for the polymorphisms were estimated by gene counting. Differences in genotype frequency distribution from that expected from Hardy-Weinberg equilibrium were determined by the chi-square test. Haplotype frequencies were estimated on the basis of the Expectation-Maximization algorithm (30) using the population genetics data analysis program Arlequin (31). The computer package SAS System 6.12 for Windows (SAS Institute Inc., Cary, NC, USA) was used to analyze data. All the continuous variables are presented as means \pm SD. In order to improve statistical power, the genotypes for C3435T (CT and TT) and G2677T/A (GT, GA, TT, TA) polymorphisms were combined into a single " $\mathrm{T}$ " allele carrier for C3435T and a single "T/A" allele carrier for G2677T/A polymorphism. Relationships between the genotypes and categorical variables (cigarette smoking, age, sex, menopause, hypertension) were evaluated by the chi-square test. The effect of each polymorphism on lipid and lipoprotein 
levels before and after atorvastatin administration $(10 \mathrm{mg} /$ day $)$ was evaluated by repeated measures ANOVA followed by the Tukey test. Serum lipid and lipoprotein data before and after treatment were compared using the profile test by contrast. All variables were $\log$ transformed $\left(\log _{10}\right)$ for analysis due to lack of normal distribution. Significance was defined as $\mathrm{P}<0.05$.

\section{Results}

\section{MDR1 polymorphisms}

The allelic frequencies and genotype distribution of the MDRI polymorphisms for the Brazilian individuals of European descent studied here are summarized in Table 2. The genotype frequencies of the MDRI polymorphisms were in Hardy-Weinberg equilibrium. The relative frequency of the MDR1 2677T allele was 0.384, while the frequency of the 2677A allele was much lower (0.036). For C3435T polymorphism, the relative frequency of the $3435 \mathrm{~T}$ allele was 0.464 . A strong linkage disequilibrium was observed between the G2677T/A and C3435T polymorphisms $\left(\chi^{2}=34.88, \mathrm{P}<\right.$ $0.0001,2$ d.f.). Association between genotypes from the MDRI polymorphisms resulted in 18 possible haplotypes, 10 of which were found in the Brazilian subjects of European descent. The most frequent haplotype was $2677 \mathrm{GT} / 3435 \mathrm{CT}$ (36.2\%), followed by GG/CC (15.9\%), GG/CT (11.5\%) and TT/ TT $(10.1 \%)$, whereas the frequency of the GT/TT (7.3\%), GT/CC (7.2\%), GA/CC (4.4\%), GG/TT and TA/CT (2.9\%), and TT/ CT $(1.5 \%)$ haplotypes was lower.

\section{Effects of MDR1 polymorphisms}

The relationships between genotypes and categorical variables (cigarette smoking, age, sex, menopause, hypertension) were evaluated by the chi-square test. There was no significant influence of the variables on genotype distribution (data not shown).

The results of repeated measures ANOVA regarding the effect of MDRI C3435T and G2677T/A polymorphisms on serum lipid and lipoprotein concentrations before and after treatment with atorvastatin are presented in Table 3. The serum lipid levels of individuals carrying the $2677 \mathrm{G}$ allele (GG genotype) were similar to those found in GG non-carriers (GT, GA, TT, AA, TA genotypes) after atorvastatin treatment $(\mathrm{P}>0.05)$. For C3435T polymorphism, 3435C carriers (CC genotype) had a lipid profile similar to that of CC non-carriers (CT and TT genotypes; $\mathrm{P}>0.05$ ).

No significant interaction between G2677T/A and C3435T MDR1 polymorphisms and atorvastatin treatment was observed regarding treatment-induced changes

\begin{tabular}{|c|c|c|c|c|c|c|c|c|c|}
\hline \multirow{2}{*}{$\begin{array}{l}\text { Polymorphism } \\
\text { G2677T/Aa }\end{array}$} & \multicolumn{6}{|c|}{ Genotype distribution } & \multicolumn{3}{|c|}{ Relative allele frequencies } \\
\hline & GG & GT & $\mathrm{TT}$ & GA & TA & AA & $\mathrm{G}$ & $\mathrm{T}$ & A \\
\hline & $30.4(21)$ & $50.7(35)$ & $11.6(8)$ & $4.3(3)$ & $2.9(2)$ & 0 & 0.580 & 0.384 & 0.036 \\
\hline \multirow[t]{2}{*}{$\mathrm{C} 3435 \mathrm{~T}^{\mathrm{b}}$} & $\mathrm{CC}$ & \multicolumn{3}{|c|}{$\mathrm{CT}$} & \multicolumn{2}{|c|}{ TT } & \multicolumn{3}{|c|}{ C } \\
\hline & $27.5(19)$ & \multicolumn{3}{|c|}{$52.2(36)$} & \multicolumn{2}{|c|}{$20.3(14)$} & \multicolumn{3}{|c|}{0.464} \\
\hline
\end{tabular}

The number of individuals is given in parentheses. Hardy-Weinberg equilibrium: ${ }^{\mathrm{P}} \mathrm{P}=0.592$; ${ }^{\mathrm{b}} \mathrm{P}=0.815$ (chisquare test). 
in lipids or lipoproteins $(\mathrm{P}>0.05)$.

We also evaluated the effect of MDRI haplotypes between baseline and atorvastatin treatment on serum concentrations of lipids

Table 3. Serum lipid levels at baseline and after atorvastatin of Brazilian hypercholesterolemic individuals of European descent according to MDR1 genotype.

\begin{tabular}{lcccc}
\hline Polymorphisms & \multicolumn{3}{c}{ Lipids and lipoprotein concentrations (mg/dl) } \\
\cline { 2 - 5 } & TC & LDL-C & HDL-C & TG \\
\hline G2677T/A & & & & \\
GG (N =21) & $280 \pm 31$ & $193 \pm 27$ & $51 \pm 12$ & $178 \pm 71$ \\
Baseline & $200 \pm 39$ & $122 \pm 34$ & $52 \pm 12$ & $130 \pm 51$ \\
Treatment & & & & \\
Non-GG (N = 48) & $298 \pm 53$ & $210 \pm 54$ & $51 \pm 15$ & $186 \pm 71$ \\
Baseline & $207 \pm 38$ & $128 \pm 37$ & $51 \pm 14$ & $142 \pm 56$ \\
Treatment & 0.2519 & 0.3294 & 0.6569 & 0.4037 \\
P (a) & 0.0001 & 0.0001 & 0.6072 & 0.0001 \\
P (b) & 0.6349 & 0.7588 & 0.7280 & 0.5576 \\
P (c) & & & & \\
C3435T & & & & \\
CC (N = 19) & $279 \pm 28$ & $191 \pm 25$ & $54 \pm 17$ & $171 \pm 68$ \\
Baseline & $192 \pm 36$ & $113 \pm 29$ & $53 \pm 16$ & $130 \pm 53$ \\
Treatment & & & & \\
Non-CC (N = 50) & $297 \pm 53$ & $210 \pm 53$ & $50 \pm 13$ & $188 \pm 72$ \\
Baseline & $210 \pm 38$ & $131 \pm 38$ & $50 \pm 12$ & $141 \pm 55$ \\
Treatment & 0.0721 & 0.0629 & 0.4335 & 0.2938 \\
P (a) & 0.0001 & 0.0001 & 0.9062 & 0.0001 \\
P (b) & 0.3622 & 0.2436 & 0.2793 & 0.9558 \\
P (c) & & & & \\
\hline
\end{tabular}

Data are reported as mean $\pm \mathrm{SD}$. TC $=$ total cholesterol; LDL-C $=$ low-density lipoprotein cholesterol; HDL-C = high-density lipoprotein cholesterol; $\mathrm{TG}=$ triglyceride; $\mathrm{N}=$ number of individuals. Baseline: measurement before atorvastatin treatment $(10 \mathrm{mg} /$ day); Treatment: measurement after atorvastatin treatment (10 mg/day).

$P$ values from repeated measures ANOVA studying the effect of: a) polymorphism (between group comparisons), b) atorvastatin treatment (within group comparisons), and c) interaction between polymorphism and atorvastatin treatment.

and lipoproteins. The individuals were grouped as T/T haplotype carriers (GT/CT, GT/TT, TT/CT, TT/TT, and TA/CT haplotypes) and non-T/T haplotype carriers (GG/ CC, GG/CT, GT/CC, GG/TT, and GA/CC haplotypes). As shown in Figure 1, baseline serum levels of total (Figure 1A) and LDL (Figure 1B) cholesterol were significantly higher in Brazilian individuals of European descent carrying the T/T haplotype (total cholesterol: $303 \pm 56$, LDL: $216 \pm 57 \mathrm{mg} / \mathrm{dl}$ ) than in those carrying the non-T/T haplotype (total cholesterol: $278 \pm 28$, LDL: $189 \pm 24$ $\mathrm{mg} / \mathrm{dl}$ ) (Tukey test: $\mathrm{P}<0.05$ ). However, after atorvastatin treatment, serum lipid and lipoprotein levels were similar for TT haplotype carriers and non-carriers.

As shown in Figure 2, there was no significant interaction between $\mathrm{T} / \mathrm{T}$ and non- $\mathrm{T} /$ $\mathrm{T}$ haplotype carriers and atorvastatin treatment-induced changes in total and LDL cholesterol in Brazilian subjects of European descent.

\section{Discussion}

Significant ethnic differences in allele frequency and genotype distribution of the MDR1 C3435T and G2677T/A polymorphisms have been shown (8). In the population of Brazilian subjects of European descent studied here, the relative frequency of the common $3435 \mathrm{C}$ allele $(0.558)$ was simi-

A rum total cholesterol (A) and lowdensity lipoprotein (LDL) cholesterol (B) according to MDR1 haplotype in Brazilian hypercholesterolemic individuals of European descent before (baseline) and after atorvastatin treatment $(10 \mathrm{mg} /$ day). T/T carriers: GT/CT, GT/TT, TT/CT, TT/TT, TA/CT haplotypes; non-TT carriers: GG/CC, GG/CT, GG/TT, GT/CC, GA/CC haplotypes. Horizontal lines in box plots represent the mean concentration of total cholesterol or LDL cholesterol. Repeated measures ANOVA/Tukey test.

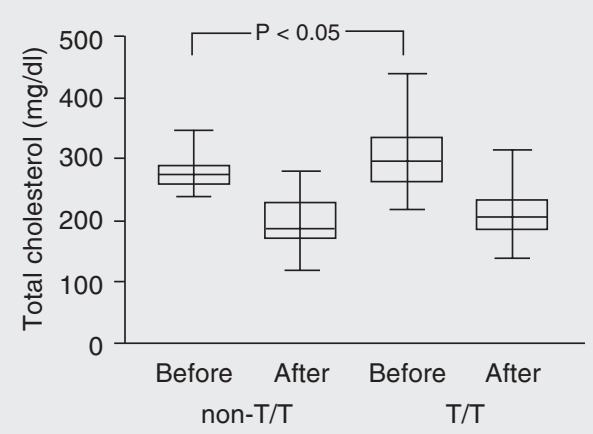

B

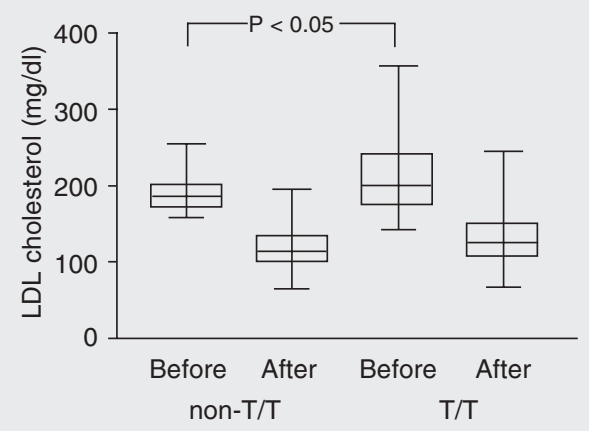


lar to that found in other Caucasian populations $(8,12,15,16,22,32)$.

Analysis of the MDR1 G2677T/A polymorphism showed that the relative frequencies of the $2677 \mathrm{G}$ (0.580), 2677T (0.384) and G2677A (0.036) alleles for Brazilians of European descent did not differ from those observed in other Caucasian populations $(8,15,16,18)$.

In our population we observed linkage disequilibrium between C3435T and G2677T/ A polymorphisms, as demonstrated for $\mathrm{Eu}-$ ropean American and Asian populations (16, 26,30,33).

High baseline levels of total and LDL cholesterol were found in Brazilian individuals of European descent carrying the $3435 \mathrm{~T}$ allele compared to those with the $3435 \mathrm{CC}$ genotype, but the results failed to reach statistical significance. Kajinami et al. (34) have reported that hypercholesterolemic white women carrying at least one 2677 nonG (2677T or 2677A) allele showed significantly higher LDL cholesterol levels than non-carriers, but this was not seen in men.

Haplotype analysis revealed that the Brazilians of European descent carrying the T/T haplotype had higher levels of total and LDL cholesterol. This observation suggests that the functional effects of P-gp may be haplotype-dependent and do not necessary need to be defined by a single polymorphism.

A

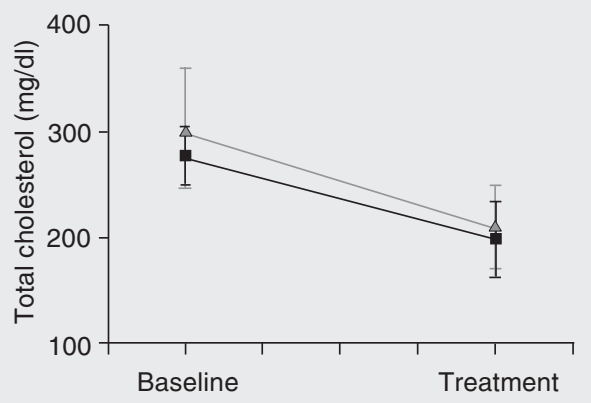

Increased MDRI mRNA and protein expression has been demonstrated $(16,20,26)$ by in vitro and in vivo studies. Nakamura et al. (20) described higher mRNA expression levels in duodenal enterocytes of healthy Japanese volunteers with the 3435TT genotype. Therefore, it is reasonable that the high levels of serum total and LDL cholesterol found in T/T haplotype carriers may be due to an increased MDRI mRNA and protein Pgp expression.

P-gp is involved in the transport of free cholesterol from the plasma membrane to the endoplasmic reticulum (ER), the site of cholesterol esterification by acyl-CoA: cholesteryl acyltransferase (ACAT) (35). In addition, the positive correlation between MDRI and ACAT mRNA expression levels found in atherosclerotic lesions suggests that P-gp may be involved in the accumulation of intracellular cholesterol ester and in the acceleration of cell proliferation rate in vessel sites prone to atherosclerosis (36).

The increased P-gp activity associated with the MDRl variants may result in increased intracellular content of cholesterol esters that induces a reduction of cholesterol synthesis and LDL uptake mediated by HMGR and LDL receptor, respectively. Therefore, the lower number of LDL receptors on the cell membrane reduces the rate of removal of LDL particles, enhancing the cholesterolemia. Although this mechanism

B

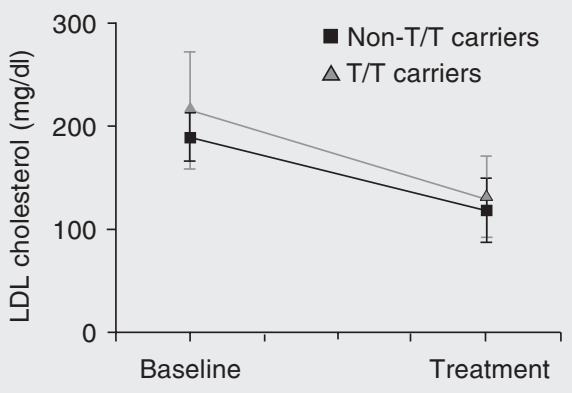

Figure 2. Serum concentration of total (A) and low-density lipoprotein (LDL) cholesterol (B) in Brazilian hypercholesterolemic individuals of European descent according to MDR1 haplotype, before (baseline) and after atorvastatin therapy (10 $\mathrm{mg} / \mathrm{day})$. Non-T/T carriers: GG/CC, GG/ CT, GG/TT, GT/CC, GA/CC haplotypes; T/T carriers: GT/CT, GT/TT, TT/CT, TT/TT, TA/CT haplotypes. Repeated measures ANOVA: $P>0.05$ for differences between non-TT and TT carriers. 
would explain the higher levels of total and LDL cholesterol found in Brazilian individuals of European descent who are T/T haplotype carriers, other molecules that regulate the intracellular cholesterol trafficking may also be involved.

Recently, it has been shown that caveolin1 , a component of caveolae, mediates the efflux of intracellular free cholesterol by transporting cholesterol from the ER to the plasma membrane (37). Therefore, the availability of a cholesterol substrate in the ER, which is the major determinant of ACAT activity, may be regulated by both P-gp and caveolin-1 (37). These findings would explain the lack of correlation between P-gp activity and intracellular cholesterol esterification found in HepG2 cells (38).

The C3435T and G2677T/A polymorphisms were associated with drug responses in patients treated with atorvastatin (34), nelfinavir (39), digoxin (22), and tacrolimus (40). We did not find a significant effect of these polymorphisms on the response to atorvastatin in hypercholesterolemic patients. Recently, Kajinami et al. (34) detected an association between 3435CC genotype and smaller reductions in LDL cholesterol, but larger increases in HDL cholesterol, relative to variant allele carriers among hypercholesterolemic white women after treatment with atorvastatin $(10 \mathrm{mg} /$ day $)$. This effect was not found in men, suggesting a gender-specific effect. Also, haplotype analysis showed that women carrying the homozygous GC haplotype (2677GG and 3435CC genotypes) have a smaller response regarding reduction of LDL cholesterol than women with the nonGC haplotype.

The lack of association between lipid response to atorvastatin and MDRl genotypes and haplotypes may be due to the size of our sample since we could not stratify our population by gender. In addition, this caused the statistical power of the test performed to be below the desired level. Therefore, other studies on P-gp expression and MDRl polymorphisms involving larger samples (at least two to three times larger) are necessary to determine whether $M D R l$ variants in fact influence P-gp expression and consequently atorvastatin disposition. In addition, the positive association between our T/T haplotype carriers and higher basal total and LDL cholesterol would be greatly strengthened if the sample were larger.

We conclude that MDRI polymorphism may have an important contribution to basal total and LDL cholesterol serum levels in Brazilian individuals of European descent with primary hypercholesterolemia.

\section{References}

1. Malinowski JM (1998). Atorvastatin: a hydroxymethylglutaryl-coenzyme A reductase inhibitor. American Journal of Health-System Pharmacy, 55: 2253-2267.

2. Igel M, Sudhop T \& Von Bergmann K (2001). Metabolism and drug interactions of 3-hydroxy-3-methylglutaryl coenzyme-A-reductase inhibitors (statins). European Journal of Clinical Pharmacology, 264: 11693-11698.

3. Jacobson W, Kuhn B, Soldner A et al. (2000). Lactonization is the critical first step in the disposition of the 3-hydroxy-3-methylglutarylCoA reductase inhibitor atorvastatin. Drug Metabolism and Disposition, 28: 1369-1378.

4. Prueksaritanont T, Subramanian R, Fang X et al. (2002). Glucuronidation of statins in animals and humans: a novel mechanism of statin lactonization. Drug Metabolism and Disposition, 30: 505-512.

5. Siest G, Ferrari L, Accaoui MJ et al. (2003). Pharmacogenomics of drugs affecting the cardiovascular system. Clinical Chemistry and Laboratory Medicine, 41: 590-599.

6. Klein I, Sarkadi B \& Varadi A (1999). An inventory of the human ABC proteins. Biochimica et Biophysica Acta, 1461: 237-262.

7. Bogman K, Peyer AK, Török M et al. (2001). HMG-CoA reductase inhibitors and P-glycoprotein modulation. British Journal of Pharmacology, 132: 1183-1192.

8. Marzolini C, Paus E, Buclin T et al. (2004). Polymorphisms in human MDR1 (P-glycoprotein): Recent advances and clinical relevance. Clinical Pharmacology and Therapeutics, 75: 13-33.

9. Gottesman MM \& Pastan I (1993). Biochemistry of multidrug resistance mediated by the multidrug transporter. Annual Review of Biochemistry, 62: 385-427.

10. Kliewer AS (2003). The nuclear pregnane $X$ receptor regulates xenobiotic detoxification. Journal of Nutrition, 133: 2444S-2447S. 
11. Lehmann JM, McKee DD, Watson MA et al. (1998). The human orphan nuclear receptor PXR is activated by compounds that regulate CYP3A4 gene expression and cause drug interactions. Journal of Clinical Investigation, 102: 1016-1023.

12. Ameyaw MM, Regateiro F, Li T et al. (2001). MDR1 pharmacogenetics: frequency of the C3435T mutation in exon 26 is significantly influenced by ethnicity. Pharmacogenetics, 11: 217-221.

13. Schaeffeler E, Eichelbaum M, Brinkmann U et al. (2001). Frequency of C3435T polymorphism of MDR1 gene in African people. Lancet, 358: 383-384.

14. Moriya Y, Nakamura T, Horinouchi M et al. (2002). Effects of polymorphisms of MDR1, MRP1, and MRP2 genes on their mRNA expression levels in duodenal enterocytes of healthy Japanese subjects. Biological and Pharmaceutical Bulletin, 25: 1356-1359.

15. Cascorbi I, Gerloff T, Johne A et al. (2001). Frequency of single nucleotide polymorphisms in the nucleotide in the P-glycoprotein drug transporter MDR1 gene in white subjects. Clinical Pharmacology and Therapeutics, 69: 169-174.

16. Kim RB, Leake BF, Choo EF et al. (2001). Identification of functionally variant MDR1 alleles among European Americans and African Americans. Clinical Pharmacology and Therapeutics, 70: 189-199.

17. Tanabe M, leri I, Nagata $\mathrm{N}$ et al. (2001). Expression of P-glycoprotein in human placenta: relation to genetic polymorphism of the multidrug resistance (MDR1) gene. Journal of Pharmacology and Experimental Therapeutics, 297: 1137-1143.

18. Furuno T, Landi MT, Ceroni M et al. (2002). Expression polymorphism of the blood-brain barrier component P-glycoprotein (MDR1) in relation to Parkinson's disease. Pharmacogenetics, 12: 529-534.

19. Gaikovitch EA, Cascorbi I, Mrozikiewicz PM et al. (2003). Polymorphisms of drug-metabolizing enzymes CYP2C9, CYP2C19, CYP2D6, CYP1A1, NAT2 and P-glycoprotein in a Russian population. European Journal of Clinical Pharmacology, 59: 303-312.

20. Nakamura T, Sakaeda T, Horinouchi M et al. (2002). Effect of the mutation (C3435T) at exon 26 of the MDR1 gene on expression level of MDR1 messenger ribonucleic acid in duodenal enterocytes of healthy Japanese subjects. Clinical Pharmacology and Therapeutics, 71: 297-303.

21. Johne A, Kopke K, Gerloff T et al. (2002). Modulation of steady-state kinetics of digoxin by haplotypes of the P-glycoprotein MDR1 gene. Clinical Pharmacology and Therapeutics, 72: 584-594.

22. Hoffmeyer S, Burk O, Von Richter O et al. (2000). Functional polymorphisms of the human multidrug-resistance gene: multiple sequence variations and correlation of one allele with P-glycoprotein expression and activity in vivo. Proceedings of the National Academy of Sciences, USA, 97: 3473-3478.

23. von Ahsen N, Richter M, Grupp C et al. (2001). No influence of the MDR-1 C3435T polymorphism or a CYP3A4 promoter polymorphism (CYP3A4-V allele) on dose-adjusted cyclosporin A trough concentrations or rejection incidence in stable renal transplant recipients. Clinical Chemistry, 47: 1048-1052.

24. Brinkmann U, Roots I \& Eichelbaum M (2001). Pharmacogenetics of the human drug-transporter gene MDR1: impact of polymorphisms on pharmacotherapy. Drug Discovery Today, 6: 835-839.

25. Kurata Y, leiri I, Kimura M et al. (2002). Role of human MDR1 gene polymorphism in bioavailability and interaction of digoxin, a sub- strate of P-glycoprotein. Clinical Pharmacology and Therapeutics, 72: 209-219.

26. Sakaeda T, Nakamura T \& Okumura K (2002). MDR1 genotyperelated pharmacokinetics and pharmacodynamics. Biological and Pharmaceutical Bulletin, 25: 1391-1400.

27. Expert Panel on Detection, Evaluation, and Treatment of High Blood Cholesterol in Adults (2001). Executive Summary of the Third Report of the National Cholesterol Education Program (NCEP) Expert Panel on Detection, Evaluation, and Treatment of High Blood Cholesterol in Adults (Adult Treatment Panel III). Journal of the American Medical Association, 285: 2486-2497.

28. Friedwald WT, Levy RI \& Fredrickson DS (1967). Estimation of the concentrations of low-density lipoprotein - an integral approach to mechanisms and disorders. New England Journal of Medicine, 276: 32.

29. Salazar LA, Hirata MH, Cavalli SA et al. (1998). Optimized procedure for DNA isolation from fresh and cryopreserved clotted human blood useful in clinical molecular testing. Clinical Chemistry, 44: 1748-1750.

30. Tang K, Ngoi SM, Gwee PC et al. (2002). Distinct haplotype profiles and strong linkage disequilibrium at the MDR1 multidrug transporter gene locus in three ethnic Asian populations. Pharmacogenetics, 12: $437-450$.

31. Arlequin software. Arlequin's home on the web. [http://lgb.unige.ch/ arlequin/]. Accessed January 2004.

32. Bernal ML, Sinues B, Fanlo A et al. (2003). Frequency distribution of C3435T mutation in exon 26 of the MDR1 gene in a Spanish population. Therapeutic Drug Monitoring, 25: 107-111.

33. Evans WE \& McLeod HL (2003). Pharmacogenomics - drug disposition, drug targets, and side effects. New England Journal of Medicine, 348: 538-549.

34. Kajinami K, Brousseau ME, Ordovas JM et al. (2004). Polymorphisms in the multidrug resistance-1 (MDR1) gene influence the response to atorvastatin treatment in a gender-specific manner. American Journal of Cardiology, 93: 1046-1050.

35. Debry P, Nash EA, Neklason DW et al. (1997). Role of multidrug resistance P-glycoproteins in cholesterol esterification. Journal of Biological Chemistry, 272: 1026-1030.

36. Petruzzo P, Cappai A, Brotzu G et al. (2001). Lipid metabolism and molecular changes in normal and atherosclerotic vessels. European Journal of Vascular and Endovascular Surgery, 22: 31-36.

37. Batetta B, Mulas MF, Sanna F et al. (2003). Role of cholesterol ester pathway in the control of cell cycle in human aortic smooth muscle cells. FASEB Journal, 17: 746-748.

38. Issandou M \& Grand-Perret T (2000). Multidrug resistance P-glycoprotein is not involved in cholesterol esterification. Biochemical and Biophysical Research Communications, 279: 369-377.

39. Fellay J, Marzolini C, Meaden ER et al. (2002). Response to antiretroviral treatment in IIIV-I-infected individuals with allelic variants of the multidrug resistance transporter I: a pharmacogenetic study. Lancet, 3359: 30-36.

40. Anglicheau D, Verstuyft C, Laurent-Puig P et al. (2003). Association of the multidrug resistance-1 gene single-nucleotide polymorphisms with the tacrolimus dose requirements in renal transplant recipients. Journal of the American Society of Nephrology, 14: 1889-1896. 